\title{
Achieving Agricultural Benefits from Biochar Application
}

\author{
Safahani Langeroodi $\mathbf{R}^{*}$ \\ Department of Agronomy, Payame Noor University, Iran
}

Submission: October 04, 2017; Published: January 08, 2018

*Corresponding author: Safahani Langeroodi R, Department of Agronomy, Payame Noor University, Tehran, Iran, Email: safahani.ali@gmail.com

\section{Opinion}

Biochar is a predominantly stable, recalcitrant organic carbon (C) compound, created when biomass (feedstock) is heated to temperatures usually between 300 and $1000{ }^{\circ} \mathrm{C}$, under low (preferably zero) oxygen concentrations [1]. Biochar application to soils is currently being considered as a means of mitigating climate change by sequestering $\mathrm{C}$, while concurrently improving soil properties and functions. Comparing the incorporation of biochar versus that of 'fresh' crop residues into soils may provide an insight into the mechanism of $\mathrm{C}$ sequestration through application of biochar to soils. Carbon dioxide from the atmosphere is fixed in vegetation through photosynthesis. Biochar is subsequently created through pyrolysis of the plant material, thereby increasing its inherent recalcitrance with respect to the original biomass. The estimated C-residence time of biochar in soils is in the range of hundreds to thousands of years, while that of cropresidue is in the range of decades [2]. Consequently, incorporating biochar from such a feedstock into soils has the potential to reduce the $\mathrm{CO} 2$ release back to the atmosphere. It is posited that, if other greenhouse gas emissions from soils are note levated as a consequence of biochar application, and if those emissions associated with production and transport of biochar and/or its feed stocks do not off-set the sequestered $\mathrm{C}$, then the overall green house effect will be abated [3]. The amount of feed stock required for conversion to biochar in order to achieve such a result, is critically dependent on the $\mathrm{C}$ retention (i.e. the ratio of the $\mathrm{C}$ in the biochar over the $\mathrm{C}$ in the initial dry biomass feedstock).Carbon retention of $49 \%$ has been reported for slow pyrolysis at atmospheric pressure, while higher C retention (100\%) resulted in less stable biochar, with residence times of 4-29 years [4].

Concomitant with carbon sequestration, biochar is intended to improve soil properties and functions relevant to agronomic and environmental performance [4]. Hypothesised mechanisms for such a potential improvement are mainly enhanced water and nutrient retention (as well as improved soil structure and drainage). Furthermore, there is experimental evidence that soil microbial communities and their activity, which hold key roles in sustaining soil health and functioning, are directly affected by the addition of biochar to soils [5]. The full range of mechanisms and consequences behind these effects remain poorly elucidated. However, it is likely that changes in soil microbial activity, community structure and functional diversity could impact on crop productivity. For example, it has been previously shown that biochar addition to soil increases N2 fixation by both free-living and symbiotic diazotrophs [6]. Whether this can be explained by an increase indiazotrophic biomass or enhanced metabolic activity is yet to be investigated. However, as $\mathrm{N}$ is often the limiting factor for crop productivity, particularly in agricultural scenarios, improved $\mathrm{N}$ fixation by soil microorganisms seems likely to explain to some extent the increase in overall crop productivity. There is a poor understanding of the general relationship between soil organic matter (SOM) and crop yield [7], the same is currently true regarding the interaction between biochar and crop productivity. In experimental field trials, it is often difficult or impossible to fully account for or control all environmental variables in an experimental design, such as meteorological factors and their annual and inter-annual variability. This can lead to weaknesses in the data obtained from these experiments, and reduce confidence when extrapolating results and formulating predictions for other probable effects under other environmental conditions.

In recent years, various factors have highlighted biochar as a relevant topic for research, as well as for policy and the wider society. In addition to mitigating climate change and offering the potential for organic waste disposal, helping to achieve food security is an important driver. The global human population is expected to increase to 9.2 billion by 2050 . Currently, more than $99 \%$ of food supplies (calories) for human consumption comes from the land FAO [8] and this seems unlikely to decrease. Verification of the effects of biochar on crop yields would, therefore, demonstrate the potential for biochar to help or hinder global food security. 


\section{References}

1. Verheijen FGA, Jeffery S, Bastos AC, van der Velde M, Diafas I (2010) Biochar Application to Soils - A Critical Scientific Review of Effects on Soil Properties, Processes and Functions. EUR 24099 EN, Office for the Official Publications of the European Communities, Luxembourg.

2. Lehmann J, Gaunt J, Rondon M (2006) Bio-char sequestration in terrestrial ecosystems-a review. Mitigation and Adaptation Strategies for Global Change 11(2): 403-427.

3. Roberts KG, Gloy BA, Joseph S, Scott NR, Lehmann J (2010) Lifecycle assessment of Biochar systems: Estimating the energetic, economic and climate change potential. Environmental Science and Technology 44: 827-833.

4. Woolf D, Amonette JE, Street-PFA, Lehmann J, Joseph S (2010) Sustainable biochar to mitigate global climate change. Nature Communications 1(56): doi:10.1038/ncomms1053.
5. Steiner C, Glaser B, Teixeira WG, Lehmann J, Blum WEH, et al. (2008) Nitro genretention and plant uptake on a highly weathered central Amazonian Ferralsol amended with compost and charcoal. Journal of Plant Nutrition and Soil Science 171(6): 893-899.

6. Rondon M, Lehmann J, Ramirez J, Hurtado M (2007) Biological nitrogen fixation by common beans (Phaseolus vulgaris L.) increases with biochar additions. Biology and Fertility of Soils 43(6): 699-708.

7. Loveland P, Webb J (2003) Is there a critical level of organic matter in the agricultural soils of temperate regions: a review. Soil \& Tillage Research 70: 1-18.

8. FAO (2003) Food Balance Sheet. 